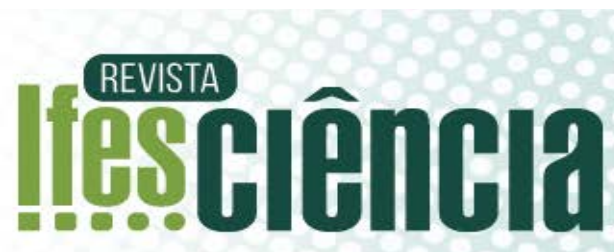

\section{TECNOLOGIA DE PREPARO DE SEMENTES DE ABÓBORA}

\author{
PUMPKIN SEED PREPARATION TECHNOLOGY
}

\author{
${ }^{1 *}$ Letícia Souza. \\ ${ }^{2}$ Robson Meireles Celestino. \\ ${ }^{3}$ Luciléa Silva dos Reis. \\ ${ }^{4}$ Stella Arndt. \\ ${ }^{1}$ Instituto Federal do Espírito Santo, Campus Santa Teresa. E-mail: leticia.17souza@outlook.com \\ ${ }^{2}$ Instituto Federal do Espírito Santo, Campus Santa Teresa. E-mail: robsoncm@ifes.edu.br \\ ${ }^{3}$ Instituto Federal do Espírito Santo, Campus Santa Teresa. E-mail: lucileasr@ifes.edu.br \\ ${ }^{4}$ Instituto Federal do Espírito Santo, Campus Santa Teresa. E-mail: stellaarndt7@gmail.com \\ *Autor de correspondência
}

Artigo submetido em 22/09/2020, aceito em 19/03/2021 e publicado em 02/07/2021.

Resumo: Objetivou-se com o presente experimento avaliar a eficiência do método de água em alta pressão utilizando uma bomba doméstica para retirada da mucilagem de sementes de abóbora. $\mathrm{O}$ experimento foi submetido aos seguintes tratamentos: T0) Fermentação por 72 horas seguidas por lavagem em peneira de arame; e submissão das sementes ao jato de água com pressão por T1) 0 Segundo (testemunha com a mucilagem); T2) 10 Segundos; T3) 20 Segundos; T4) 30 Segundos; T5) 40 Segundos: T6) 50 Segundos. As sementes foram avaliadas de acordo com as seguintes variáveis de germinação e de vigor: Teste de germinação, primeira contagem de germinação, massa da matéria fresca/seca da plântula, comprimento de raiz e de parte aérea. O delineamento utilizado foi o inteiramente casualizado (DIC) com quatro repetições, sendo cada uma constituída por 50 sementes. O método de jato de água em alta pressão para a retirada da mucilagem de sementes de abóbora apresenta maior eficiência que os demais, pois mantêm a mesma qualidade, sendo ainda um processo mais rápido. Os tempos de submissão ao jato d'água que proporcionam os melhores desempenhos de germinação e de vigor variam de 10 a 50 segundos. Dessa forma, conclui-se que a retirada da mucilagem de sementes de abóbora pode ser efetuada por meio de jatos d’água em alta pressão, sendo eficiente a partir de 10 segundos de submissão.

Palavras-chave: Mucilagem; Fermentação; Cucurbita.

Abstract: The objective of the present experiment was to evaluate the efficiency of the high pressure water method using a domestic pump to remove mucilage from pumpkin seeds. The experiment was submitted to the following treatments: T0) Fermentation for 72 hours followed by washing on a steel sieve; the seeds were submitted to high pressure showers for T1) 0 seconds (witnessing the mucilage); T2) 10 seconds; T3) 20 seconds; T4) 30 seconds; T5) 40 seconds; T6) 50 seconds. The seeds were evaluated according to the following variations in germination and vigor: Germination test, first germination counting, mass of fresh/dried material from the plantule, root and aerial part length. The applied outline was entirely random (DIC) with four repetitions, each one consisting of 50 seeds. The method of water in high pressure to remove the mucilage from pumpkin seeds presents more 
efficiency than others, for it maintains the same quality, yet delivering a faster process. The periods for exposure to the water showers that deliver the best germination and vigor performances vary between 10 and 50 seconds. Therefore, the removal of mucilage from pumpkin seeds may be carried out through water showers in high pressure, it being efficient up to 10 seconds of exposure.

Keywords: Mucilage; Fermentation; Cucurbita.

\section{INTRODUÇÃO}

A qualidade das sementes é um dos principais fatores que interferem a produção de grãos, em virtude do melhoramento genético. O Brasil tem sido considerado um dos países que possuem melhores condições para adaptação e produção das mesmas. Um dos setores agrícolas que tem crescido comercialmente é o setor da olericultura, sendo destaque na produção e, consequentemente, na alta movimentação de capital (DE CAMPANTE SANTOS et al., 2014).

A produção de olerícolas tem movimentado bastante o mercado brasileiro de sementes, sendo reconhecidas pela boa qualidade fisiológica e desenvolvimento. As cultivares que possuem frutos carnosos como a abóbora necessita da retirada da mucilagem, podendo esta ser efetuada por diferentes procedimentos para que não haja nenhuma interferência na sua germinação e vigor.

De acordo com Oliveira et al., (2012), a presença da mucilagem é uma barreira que impede a eficácia do metabolismo das sementes, principalmente por constituir de alguns compostos capazes de inibir a passagem de oxigênio dificultando o processo germinativo. A remoção da mesma mantém o potencial fisiológico, sendo um fator de extrema importância para o desenvolvimento das culturas, uniformidade das populações, vigor das plântulas e ausência de doenças.

Usando jato de água em alta pressão, Ferreira et al. (2015) já comprovaram a eficiência do método para a remoção da mucilagem das sementes de mamão. Já Cavalcante et al. (2014) também trabalhando com o mamoeiro, observaram que a retirada manual com o auxílio de peneira de arame teve um bom desempenho.
Em decorrência da defasagem de comprovação de métodos alternativos de remoção da mucilagem das sementes de abóbora que não alteram o potencial fisiológico das sementes, objetivou-se com o presente trabalho avaliar eficiência do jato d'água em alta pressão na remoção da mucilagem das sementes da espécie em estudo.

\section{REFERENCIAL TEÓRICO}

Nas culturas onde a produção de sementes são tecnificadas, os cuidados vão desde a implantação no campo até o armazenamento e comercialização. Em relação aos tratamentos de pós-colheita, a retirada da mucilagem proporciona que as sementes mantenham sua qualidade e possibilita o estabelecimento uniforme do vigor das mesmas.

Em espécies onde a retirada da mucilagem é mais pesquisada, é comum encontrar trabalhos de comparações de diferentes métodos, como por exemplo o de Melo e Seleguini (2013) e o de Cavalcante et al. (2014), que trabalharam com a cultura do mamão.

Apesar de os métodos serem semelhantes e possuírem os mesmos princípios, os resultados variam de uma cultura para outra. Na cultura do mamão, Cavalcante et al. (2014) tinham como objetivo determinar o melhor método de remoção da sarcotesta, utilizando os tratamentos de remoção com pressão sobre peneira, remoção pela fricção com areia autoclavada, remoção com liquidificador e testemunha com mucilagem, onde concluíram que a remoção da sarcotesta em peneira foi a mais eficaz.

Para a cultura da abóbora, são pouquíssimos os trabalhos comparando os métodos de remoção de mucilagem. Autores como Nascimento et al. 
(2011) empregaram métodos físicos e químicos, respectivamente, como formas de retirada de mucilagem. Ferreira et al. (2015), utilizando jato de água em alta pressão, mostraram um método eficaz para a remoção da mucilagem das sementes de mamão. Já Cavalcante et al. (2014), trabalhando também com sementes de mamão, observaram que a retiradas manualmente com o auxílio de peneira de arame teve o melhor desempenho.

Trabalhando com o método de jato de água em alta pressão, Brumat et al. (2015), na cultura do maracujá, buscaram qual seria o tempo de exposição que proporcionaria os melhores resultados de germinação, em comparação com o método de remoção manual com auxílio de peneira de arame. Puderam assim verificar que o tempo de 2 minutos de exposição foi maior que a retirada manual. Pesquisando a eficiência do método citado acima, na cultura do mamão, Ferreira et al. (2015) determinaram que o tempo de 1 minuto e 30 segundos seria o mais eficiente para as sementes.

Sendo assim, é necessário realizar pesquisas em espécies de cultivares que produzem sementes com sarcotesta e que ainda são retiradas por métodos convencionais, com intuito de minimizar o tempo de aplicação dos mesmos mantendo os mesmos níveis de qualidade.

\section{MATERIAIS E MÉTODOS}

O trabalho foi conduzido no Laboratório de Tecnologia e Produção de Sementes do Instituto Federal do Espírito Santo Campus Santa Teresa, no período de março a abril de 2017. As sementes de abóbora utilizadas foram da variedade jacarezinho, adquiridas em uma propriedade de São Roque do Canaã, colhidas no estágio de maturação fisiológica com o parâmetro de coloração do fruto.

As sementes da cultivar foram submetidas ao jato de água com o auxílio de uma máquina de 1450 Psi. Foram usadas peneiras com 0,3 metros de comprimentos e 0,1 de largura. As sementes ficaram entre duas peneiras com auxílio de parafusos.

Os tratamentos utilizando o jato de água com alta pressão foram: T0: fermentação por $72 \mathrm{~h}$ seguindo por lavagem em peneira de arame; T1: 0 segundos (Testemunha com mucilagem); T2: 10 segundos; T3: 20 segundos, T4: 30 segundos; T5: 40 segundos e T6: 50 segundos.

Após as aplicações as sementes passaram pelo processo de secagem até atingirem seu peso constante, sendo avaliadas com parâmetros de germinação e vigor. Foi realizado testes de germinação com quatro repetições contendo 50 sementes, as quais ficaram mantidas na câmara de germinação do tipo BOD com temperatura alternada de $20-30^{\circ} \mathrm{C}$ (16h de escuro e $8 \mathrm{~h}$ de luz) por 8 dias. A primeira contagem ocorreu no quarto dia após a implementação do teste, apresentando protrusão da raiz primaria com $2 \mathrm{~mm}$.

O peso da matéria fresca e seca da plântula foi obtido utilizando papel germitest umedecido com água destilada na proporção de 2,5 vezes a massa do papel seco. Para compor o experimento foram montadas quatro repetições de 10 sementes, mantidas no germinador tipo BOD em temperatura entre $20-30^{\circ} \mathrm{C}$ (16h de escuro e 8 h de luz) por oito dias. Em seguida, as mesmas foram postas em uma temperatura de $72^{\circ} \mathrm{C}$ na estufa de secagem com circulação de ar durante 72h. Findado o período em estufa, foram levadas a um dessecador e resfriadas para obtenção do peso total da matéria seca. O comprimento da raiz foi medido com apoio do teste de vigor, onde foram realizadas medições do comprimento de raiz e parte aérea, com apoio de uma régua. Os resultados obtidos foram expressos em centímetros.

O delineamento experimental usado foi o inteiramente casualizado com quatro repetições, sendo as variáveis avaliadas quanto aos pressupostos de normalidade e homocedasticidade (Lilliefors para 
normalidade, Barttlet para homocedasticidade e 0 teste não paramétrico de Kruskal Wallis para variáveis que não atenderam os pressupostos), para a posterior análise de variância. Dada a diferença qualitativa, que representa o desempenho dos tratamentos quando se trata da fermentação e dos testes de germinação, obtida da decomposição das somas dos quadrados dos tratamentos na análise de variância quando contrastados os tratamentos de fermentação das sementes T0 com os demais (T1 a T6), suas comparações foram estabelecidas por meio do contraste entre os tratamentos (T0 contra os demais)

\section{RESULTADOS E DISCUSSÃO}

Na Figura 1 estão presentes os resultados de massa fresca das plântulas de abóbora, levando em consideração o tratamento de fermentação por 72 horas como comparativo e os diferentes tempos de submissão do jato de água em alta pressão sendo eles os tratamentos: 0 segundos; 20 segundos; 30 segundos; 40 segundos e 50 segundos.

Nela é possível notar que o ponto máximo da curva de regressão ocorre aos 25,2 segundos de aplicação do jato de água em oriundo das decomposições das somas de quadrados dos tratamentos na análise de variância. A avaliação dos efeitos das comparações entre os tratamentos T1, T2, T3, T4, T5 e T6 relacionados ao tempo de trabalho da máquina foi realizada por meio de polinômios ortogonais, adotando-se um “ $\alpha$ " igual a 0,05 .

As análises das variáveis de massa fresca, de massa seca e de tamanho de parte aérea, tiveram um resultado positivo, seguindo os pré-requisitos do teste de normalidade. A estatística foi realizada por meio do programa Sisvar 5.6 (FERREIRA, 2015) e Assistat 7.7 (E SILVA, 2013).

alta pressão, que possibilitou a obtenção de uma massa média por planta de 6,9 mg, enquanto a fermentação obteve uma massa média de 6,8 mg, provavelmente os resultados dos demais tratamentos acima do ponto máximo podem ter causado alguma deterioração na semente, assim como os resultados abaixo da curva podem ter sido influenciados pela remoção ineficiente da mucilagem devido à pouca exposição das sementes ao método.

Figura 1: Massa fresca de plântulas de abóbora, compondo a avaliação de regressão.

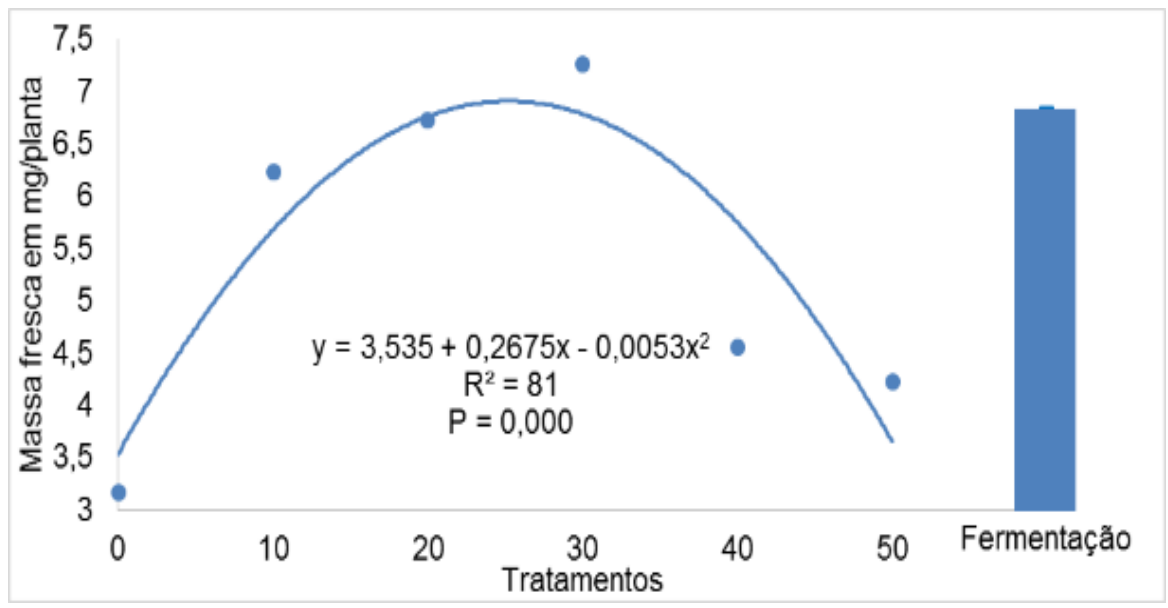

Fonte: Autoria própria.

De acordo com Freitas et al. (2011), a presença da mucilagem pode ser prejudicial à germinação e ao 
desenvolvimento das plântulas por favorecer a incidência de microorganismos ou conter substâncias inibidoras do metabolismo germinativo. Os restos da mesma podem reduzir a qualidade fisiológica das sementes caso haja alguma substancia inibidora da germinação, assim como na cultura do mamão (DIAS et al., 2017). Pesquisas demonstraram que o tempo de fermentação de sementes de qualquer espécie pode ser excedido até 144 horas sem causar danos à germinação (RICON et al., 2015).

A figura 2 é referente à massa seca levando em consideração o tratamento de fermentação por 72 horas como comparativo e os diferentes tempos de submissão do jato de água em alta pressão sendo eles os tratamentos: 0 segundos; 10 segundos; 20 segundos; 30 segundos; 40 segundos e 50 segundos

A mesma segue uma padronização semelhante à da massa fresca, não apresentando nenhuma diferença significativa em relação a fermentação. Dessa forma, não há discrepância na eficácia entre os tratamentos. O ponto de máximo fica aos 26 segundos, com a massa média de 0,687 mg por planta, os resultados que ficaram abaixo desse ponto, possivelmente foram menores devido à presença de sarcotesta.

Figura 1: Massa seca de plântulas de abóbora, compondo a avaliação de regressão.

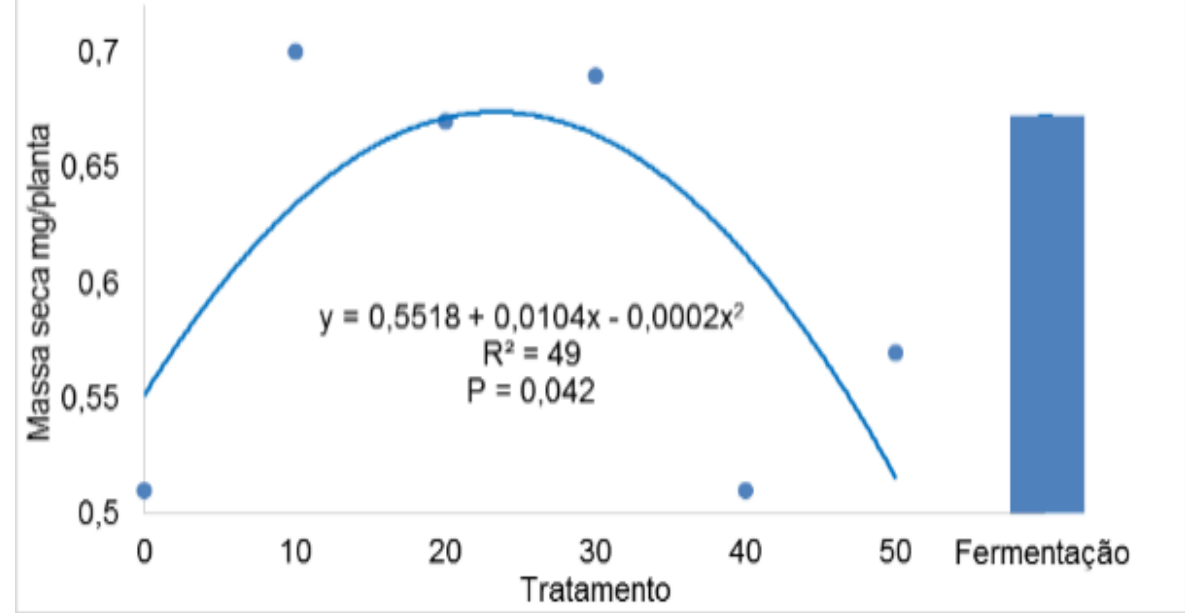

Fonte: Autoria própria.

É notória a visualização das perdas em todas as variáveis analisadas pela análise de regressão, devido ao excesso de exposição das sementes ao jato de água em alta pressão nos resultados acima do ponto de máxima. Esse tempo de exposição ao jato de água pode ter provocado perdas de reservas.

$\mathrm{Na}$ figura 3, é analisado o comprimento médio da parte aérea de plântulas de abóbora, levando em consideração o tratamento de fermentação por 72 horas como comparativo e os diferentes tempos de submissão do jato de água em alta pressão, sendo eles os tratamentos: 0 segundos; 10 segundos;20 segundos; 30 segundos; 40 segundos e 50 segundos. Observa-se que o mesmo chega ao ponto máximo aos 30,6 segundos com comprimento de $5,41 \mathrm{~cm}$. 
Figura 2: Comprimento médio da parte aérea de plântulas de abóbora, compondo a avaliação de regressão.

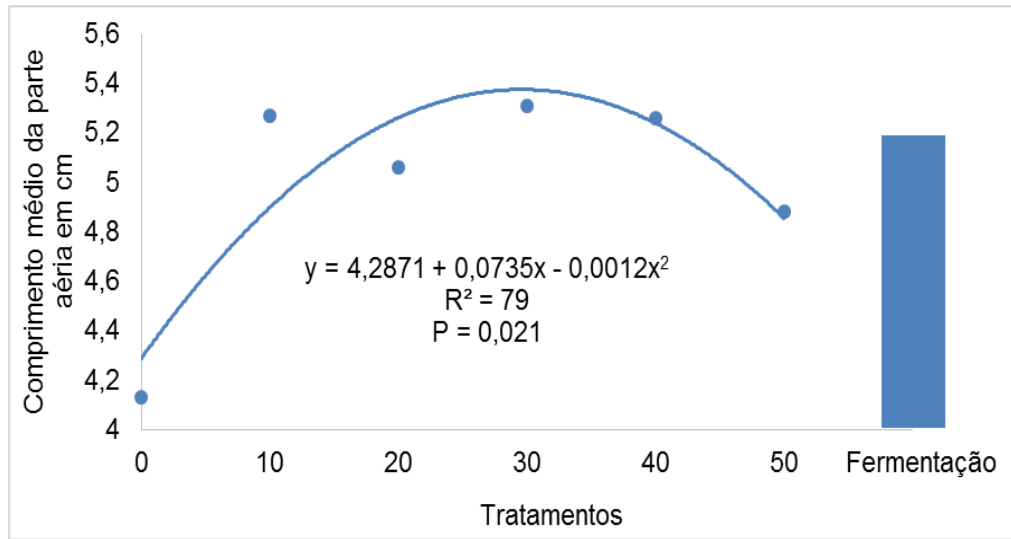

Fonte: Autoria própria.

De acordo com Cavalcante et al., (2014), a sarcotesta compromete negativamente o índice de velocidade de germinação e a emergência das sementes de mamoeiro. Dessa forma, entende-se que quanto maior o período de fermentação maior será a qualidade das sementes devido aos processos bioquímicos que fazem parte do desenvolvimento das mesmas.

Na Figura 4 estão presentes as porcentagens de germinação de sementes de abóbora, levando em consideração o tratamento de fermentação por 72 horas (tratamento 1) e os diferentes tempos de submissão do jato de água em alta pressão, sendo eles os tratamentos: $2=(0$ segundos); $3=$ (10 segundos $) ; 4=(20$ segundos $) ; 5=(30$ segundos $) ; 6=(40$ segundos $) ; 7=(50$ segundos $)$. Os valores entre parênteses são referentes a porcentagem de germinação.

Mesmo tendo relação entre os testes de vigor e germinação (figura 4), sendo estes comparados estatisticamente com o tratamento de fermentação, vale pontuar que o método de remoção da mucilagem em jato de água em alta pressão pode ser mais proveitoso em comparação com a fermentação por 72 horas, devido à menor demanda de tempo.

Figura 3: Porcentagem de germinação de sementes de abóbora, comparados pelo teste de KRUSKAL-WALLIS.

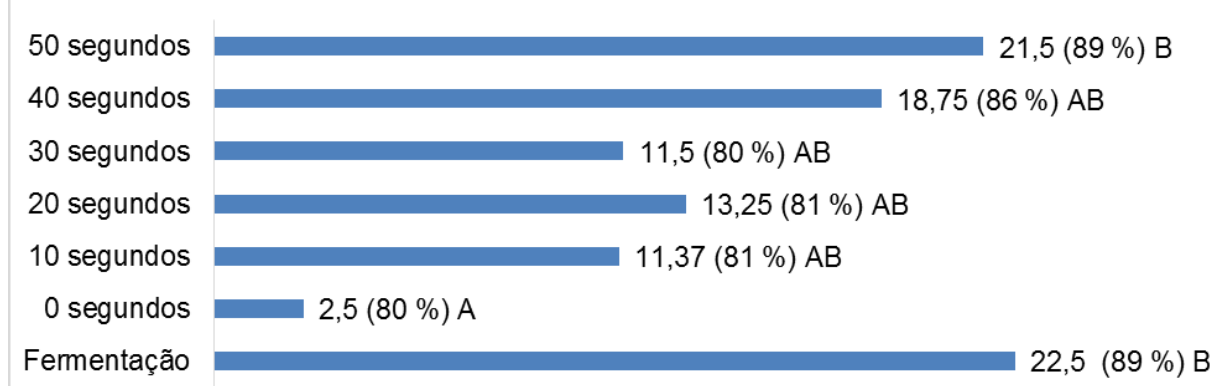

Fonte: Autoria própria.

A porcentagem de germinação, levando-se em consideração o tratamento de fermentação por 72 horas, possivelmente, só não foi semelhante 
estatisticamente quando comparado ao tratamento sem remoção de sarcotesta, bem como o tratamento de 50 segundos de submissão ao jato d'agua. A metodologia de alta pressão pode ocasionar a mesma eficiência que o método de fermentação sendo de extrema importância, não havendo perdas na qualidade fisiológica.

Brumat et al. (2015) utilizaram o método de jato de água em alta pressão nas sementes de mamão e maracujá. Nesse experimento houve uma melhora na retirada da mucilagem e ganhos relacionados ao processo de germinação das mesmas.

Investigações relacionadas à remoção da sarcotesta são escassas, como também a utilização de tratamentos prégerminativos de ácido giberélico (GA3). Em pesquisa realizada por Osipi et al. (2018) foram utilizados os seguintes tratamentos: 1) lavagem manual em peneira e água corrente; 2) repouso em solução de cal virgem, durante 24 h; e 3) fermentação em sacarose, por 72 h. A degomagem com cal virgem foi eficiente, removendo de modo fácil e rápido toda sarcotesta das sementes, proporcionando maior velocidade $(4,26)$ e percentual $(60 \%)$ de germinação às mesmas. O tratamento com cal virgem associado à aplicação de GA3 promoveu um incremento no percentual de germinação (70\%), contribuindo para melhor superação da dormência.

Na Figura 5 estão presentes valores da primeira contagem de germinação de sementes de abóbora, levando em consideração o tratamento de fermentação por 72 horas (tratamento 1) e os diferentes tempos de submissão do jato de água em alta pressão, sendo eles os tratamentos: $2=$ ( 0 segundos $) ; 3=(10$ segundos $) ; 4=(20$ segundos $) ; 5=(30$ segundos $) ; 6=(40$ segundos); 7 = (50 segundos). Os valores entre parênteses são referentes a porcentagem de germinação.

É possível visualizar que o tempo de 40 segundos é discrepante dos tratamentos de 10 e 30 segundos, onde os mesmos tiveram pouco tempo de exposição ao jato de água em alta pressão, não satisfazendo as expectativas. $\mathrm{E}$ os demais tratamentos obtiveram valores semelhantes, inclusive o tratamento de fermentação.

Figura 4 - Primeira contagem de germinação de sementes de abóbora, comparados pelo teste de KRUSKAL-WALLIS.

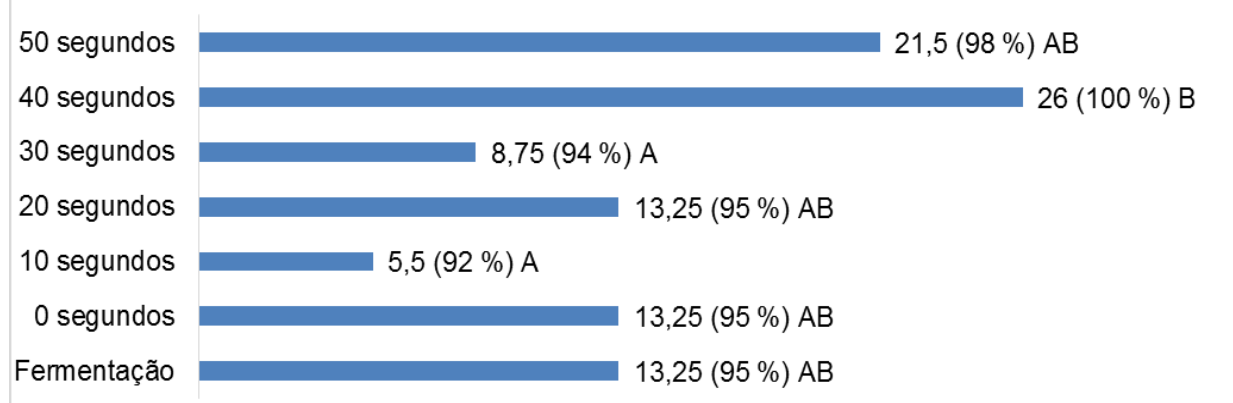

Fonte: Autoria própria.

$\mathrm{Na}$ figura 6, estão presentes os valores de comprimento de raiz de plântulas de abóbora, levando em consideração o tratamento de fermentação por 72 horas (tratamento 1) e os diferentes tempos de submissão do jato de água em alta pressão, sendo eles os tratamentos: $2=$ (0 segundos); $3=(10$ segundos $) ; 4=(20$ segundos $) ; 5=(30$ segundos $) ; 6=(40$ segundos); $7=$ (50 segundos). Os valores entre parênteses são referentes ao tamanho médio em $\mathrm{cm}$.

Observa-se que não houve diferença de comprimento de raiz, sendo que $\mathrm{o}$ fato de não haver diferenças significativas entre os resultados do 
método da fermentação e do método de jato de água em alta pressão é importante, principalmente pelo método alternativo ser de simples execução.

Figura 5: Comprimento de raiz de plântulas de abóbora, comparados pelo teste de KRUSKAL-WALLIS.

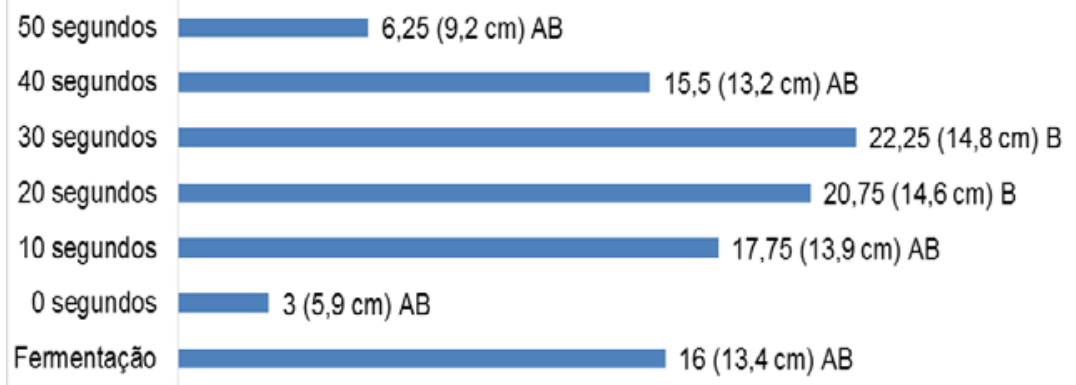

Fonte: Autoria própria.

Os tratamentos 20 e 30 segundos apresentaram resultados bem próximos, e os outros com poucas diferenças, mas não discrepantes, sendo que os tratamentos de 10, 40 segundos e fermentação, obtiveram resultados próximos e os tratamentos de 0 e 50 segundos também. Pode-se considerar que o tratamento de 0 segundos não apresentou resultado esperado devido à presença de sarcotesta e o tratamento de 50 segundos houve possivelmente algum dano mecânico devido ao excesso de tempo de exposição das sementes ao método.

\section{CONCLUSÕES}

Os tratamentos entre 10 e 50 segundos do método de jato de água em alta pressão se mostrou mais rápido e com o mesmo nível de eficiência que o método de fermentação.

O jato d’água com pressão não prejudicou a germinação e vigor das sementes de abóbora.

\section{REFERÊNCIAS}

BRUMAT, Ana Elisa Lyra et al. Retirada da sarcotesta de sementes de maracujá (Passiflora sp) com água em alta pressão com diferentes tempos de submissão. XIX Congresso Brasileiro de Sementes, Informativo ABRATES, Londrina v.25, n.2, Setembro, 2015.
CAVALCANTE, Jerffeson Araujo et al. Qualidade Fisiológica de Sementes de Mamão Submetidas a Diferentes Métodos de Remoção da Sarcotesta. Revista Verde de Agroecologia e Desenvolvimento Sustentável, v. 9, n. 2, p. 285-290, 2014. DE CAMPANTE SANTOS, Paulo Eduardo et al. Semente é tecnologia. AgroANALYSIS, v. 34, n. 3, p. 31-37, 2014.

DIAS, Maristela Aparecida et al.

Qualidade e compostos fenólicos em sementes de mamão alterados pela colheita e maturação dos frutos. Ciência Rural, v. 45, n. 4, p. 737-743, 2015.

E SILVA, Francisco de Assis Santos. Assistat 7.7. UFCG, Campina Grande, 2013.

FERREIRA, Daniel Furtado. Sisvar. Versão 5.6. Lavras: UFLA/DEX, 2015. FERREIRA, Guilherme Antônio et al. Retirada da sarcotesta com água em alta pressão com diferentes tempos de submissão. XIX Congresso Brasileiro de Sementes, Informativo ABRATES, Londrina v.25, n.2, Setembro, 2015. FREITAS, Sílvio de Jesus et al. Métodos de remoção da sarcotesta na germinação de sementes de jaracatiá. Revista Árvore, Viçosa-MG, v.35, n.1, p.91-96, 2011. MELO, Aniela Pilar Campos de; SELEGUINI, Alexsander. Estádio de maturação de frutos e remoção física da sarcotesta na produção de mudas de 
mamão. Comunicata Scientiae, v. 4, n.1, p. 20-25, 2013.

NASCIMENTO, Warley Marcos; PESSOA, Homero; SILVA, Patrícia.

Produção de sementes hibridas de abóbora do tipo tetsukabuto. Embrapa Hortaliças. Porto Alegre, 2011.

OLIVEIRA, Glauce Portela et al. Avaliação física, fisiológica e sanitária de sementes de soja de duas regiões de Mato Grosso. Revista Agrarian, v. 5, n. 16, p. 106-114, 2012.

OSIPI, Elisete Aparecida Fernandesn et al. Sarcotesta removal methods and GA3 treatment on germination of Punica granatum L. seeds. Biotemas, v. 31 n. 2, p. 1-8, 2018.

OLIVEIRA, Lucicléia Mendes et al. Períodos e ambientes de secagem na qualidade de sementes de Genipa americana L. Semina: Ciências Agrárias, v. 32, n. 2, p. 495-502, 2011.

RINCON, Natália Santana et al. Período de fermentação de sementes de maracujazeiro-amarelo na produção de mudas. IV Congresso Estadual de Iniciação Científica do IF Goiano, setembro de 2015.

DE SOUZA, Andréa Dantas; AOYAMA, Elisa Mitsuko; FURLAN, Marcos Roberto. Tempo e condição de armazenamento das sementes na germinação e desenvolvimento de Passiflora ligularis Juss. Revista em Agronegócio e Meio Ambiente, Maringá. v.8, n.1, p. 181-192, jan./abr. 2015. 